\title{
Biological Dosimetry Using Micronucleus Assay in Simulated Partial-Body Exposure to lonizing Radiation
}

\author{
S. Purnami, S. Nurhayati, M. Syaifudin and D. Ramadhani ${ }^{\star}$ \\ Center for Radiation Safety Technology and Metrology, National Nuclear Energy Agency \\ Jl. Lebak Bulus Raya No. 49, Jakarta 12440, Indonesia
}

\section{ARTICLE INFO}

Article history:

Received 15 November 2015

Received in revised form 03 August 2016

Accepted 05 December 2016

Keywords:

Biodosimetry

Micronucleus

Partial body exposure

Radiation

Simulation

\begin{abstract}
A B S T R A C T
In radiation accidents, it is common that only several parts of the body are exposed to radiation. As a consequence there is a mixture of exposed and unexposed lymphocytes in peripheral blood cells of the samples. This phenomenon will cause the dose value estimated using the exposed lymphocytes to be lower than the actual dose. In this study, an assessment of partial body exposures using micronucleus assay by estimating the partial body dose and fraction of irradiated blood was conducted. An optimal $D_{0}$ value also has been determined in this study to estimate the fraction of irradiated cells. Peripheral blood lymphocytes (PBLs) from three healthy donors were irradiated in vitro with 2 Gy of X-rays. Partial radiation exposure was simulated by mixing the irradiated and non-irradiated blood in different proportions. The proportions of mixtures of blood samples irradiated in vitro were $5,10,15,20$, and $30 \%$. Blood samples were then cultured and harvested based on micronuclei assay protocol. At least 2000 binucleated cells with wellpreserved cytoplasm were scored for the MN frequency. Dose Estimate 5.1 software was used to calculate the dispersion index $\left(\sigma^{2} / y\right)$ and normalized unit of this index $(U)$ in each proportion of bloods. The fractions of irradiated cells were calculated with CABAS (Chromosomal Aberration Calculation Software) for several different $D_{0}$ values $(2.7 ; 3.8 ; 5.4)$. The results showed that $D_{0}$ value at 5.4 gave the closest results to the actual proportion of irradiated bloods, while for the dose estimation the estimated doses value from all proportions in all donors were higher than the actual dose. The factor that may cause this phenomenon was that the dose response calibration curve used to predict the radiation dose was not constructed in the laboratory used. Overall it can be concluded that a biodosimetry using $\mathrm{MN}$ assay can be used to estimate the radiation dose in partial body exposure. In order to establish a biodosimetry using $\mathrm{MN}$ analysis the dose-response calibration curve $\mathrm{MN}$ analysis should be constructed first in the laboratory used.
\end{abstract}

(C) 2017 Atom Indonesia. All rights reserved

\section{INTRODUCTION}

The radiation doses absorbed and distributed into the bodies of radiation accident casualties are important to guide immediate medical treatment, further health care, and prognosis of exposure casualties [1]. In radiation accidents, the exposure mostly occurs only to part of the body and as a result there is a mixture of exposed and unexposed lymphocytes in peripheral blood samples [2].

\footnotetext{
* Corresponding author.

E-mail address: dhani02@batan.go.id

DOI: https://doi.org/10.17146/aij.2017.405
}

Since the exposed and unexposed lymphocytes are mixed, the dose received by the exposed lymphocytes and the dose delivered locally could be underestimated [3]. Discrimination between victims that are exposed for the whole body with those that are exposed partially is important as they will have different clinical outcomes, and it affects the medical care to treat them [4]. Until now, there are two mathematical models that have been developed to assess the dose according to the fraction of exposed lymphocytes, i.e., Qdr and Dolphin's models. Both models have been validated in vitro by mixing irradiated and unirradiated blood in different 
proportions and have also been tested in vivo in accident situations, with promising results $[3,5]$.

Several studies have been conducted to estimate the radiation dose that is received partially by radiotherapy patients. Silva-Barbosa et al., study showed that chromosomal aberrations and micronuclei (MN) quantification in lymphocytes from peripheral blood of cervical uterine cancer patients before and after receiving $0.08 \mathrm{~Gy}$ and $1.8 \mathrm{~Gy}$ was a potentially advantageous methodology of dose assessment especially in partial body exposure to ionizing radiation [6]. Another study, conducted by Senthamizhchelvan et al., revealed that biological dosimetry using micronuclei (MN) assays was applicable for dose estimation in therapeutic irradiation of cancer patients in acute high dose partial body irradiation [7].

Biological dosimetry (biodosimetry) is an investigation of biological effects (bioindicators) induced by radiation in order to correlate them with the radiation dose. Scoring of unstable chromosome aberrations (dicentrics, rings, and fragments) is considered as the most reliable method for evaluating individual exposure, and is specific to radiation exposure [8-10]. Another well known bioindicator of radiation damage is $\mathrm{MN}$ in peripheral blood lymphocytes [11]. Micronucleus are chromosome fragments that lag behind during anaphase and are not included in the main nucleus during telophase. They appear as small nuclei and can be identified during cell binucleation in the division of mitogen-activated human lymphocytes by blocking cytokinesis [5-7].

In this study, an assessment of partial-body exposures using MN assay was conducted, including the estimations of partial-body dose and fraction of irradiated blood. An optimal $D_{0}$ value has also been determined in this study to estimate the fraction of irradiated cells.

\section{EXPERIMENTAL METHODS}

\section{Blood sampling, irradiation process and simulated partial-body irradiation}

Since the focus of this study was to estimate the partial-body dose exposures using MN assay, we only used three samples that consisted of one male and two females without history of smoking habit and ionizing radiation exposure beyond routine diagnostic exposures. The reason that both male and female samples were used in this study was that it was decided that it was necessary to know whether the gender factor influenced the predicted dose value in partial-body exposure. Peripheral blood samples from all donors were collected in heparinized vacutainers. The characteristics of the donors are presented in Table 1. The blood samples were irradiated in vitro at the Secondary Standard Dosimetry Laboratory at Center for Radiation Safety Technology and Metrology, National Nuclear Energy Agency of Indonesia. Blood samples were exposed to X-ray (YXLON MG325) at $122 \mathrm{kV}$ using additional filters of $1.66 \mathrm{~mm} \mathrm{Cu}$ and $1 \mathrm{~mm} \mathrm{Al}$ with an HVL of $2.52 \mathrm{~mm} \mathrm{Cu}$ at 2 Gy with a dose rate $0.17 \mathrm{~Gy} / \mathrm{min}$. The radiation dose used in this study was 2 Gy because this is commonly used as a radiotherapy dose fractionation. After irradiation, the blood samples were maintained at $37{ }^{\circ} \mathrm{C}$ for one hour to enable repair of chromosomal damages. To simulate partial-body exposures the irradiated blood was mixed with non-irradiated blood to final proportions of 5, 10, 15, 20, and $30 \%$.

Table 1. Characteristics of the donor samples.

\begin{tabular}{cccc}
\hline Gender & Age & $\begin{array}{c}\text { Smoking Habit } \\
\text { (yes; no) }\end{array}$ & $\begin{array}{c}\text { X-ray medical } \\
\text { diagnostics } \\
\text { within } \\
\text { the last year } \\
\text { (yes; no) }\end{array}$ \\
\hline Male & 30 & No & No \\
\hline Female & $43 \& 52$ & Yes $(0)$ No $(2)$ & Yes $(0)$ No $(2)$ \\
\hline
\end{tabular}

\section{Calibration of irradiation facilities}

The measurement of air kinetic energy released in material (kerma) was done before the $\mathrm{X}$-ray machines were applied for irradiating blood samples using an NE Technology type 2570 Farmer dosimeter and a type 2571 ionization chamber. Measurement of air kerma was done in the air at the source-to-sample-center distance of $100 \mathrm{~cm}$, and the radiation field was $10 \mathrm{~cm}$. The air kerma from X-ray track was calculated using the equation given in IAEA Technical Reports Series No. 277.

\section{Blood culture}

Blood cultures $(0.5 \mathrm{~mL})$ were set up in Roswell Park Memorial Institute (RPMI 1640) culture medium supplemented with HEPES and L-Glutamine, $15 \%$ Fetal Bovine Serum (FBS), Penicillin-Streptomycin, and Phytohaemagglutinin (PHA). The cultures were maintained in a $5 \%$ humidified $\mathrm{CO}_{2}$ incubator at $37{ }^{\circ} \mathrm{C}$ for $72 \mathrm{~h}$. After incubation for $44 \mathrm{~h}, 15 \mu \mathrm{l}$ of cytochalasin B (Sigma-Aldrich) solution in DMSO (Sigma-Aldrich) was added to cultures, and cultivation was continued for another $24 \mathrm{~h}$. The cultures were then treated with 
cold hypotonic solution $(0.075 \mathrm{M} \mathrm{KCl})$ to lyse red blood. The fixative consisting of methanol:acetic acid (10:1) diluted with Ringer's solution $(\mathrm{NaCl}$, $\mathrm{KCl}, \mathrm{CaCl}_{2}$ ) should be added to replace the hypotonic solution. Then, the supernatant was washed with fixative solution twice or three times until the cell suspension is clear. The cells were then resuspended gently and the suspension dropped onto clean glass slides and allowed to dry. The slides were then stained with $4 \%$ Giemsa's solution in a potassium phosphate buffer ( $\mathrm{pH}$ 7.3) and allowed to dry overnight. The slides were mounted with cover slip and allowed to dry completely before scoring. The slides were then analyzed, and identification of $\mathrm{MN}$ was conducted according to the scoring criteria in IAEA publication [5]. At least 2000 binucleated cells with well-preserved cytoplasm were scored for the $\mathrm{MN}$ frequency.

\section{Statistical Analysis}

The dispersion index $\left(\sigma^{2} / y\right)$ and also the normalized unit of this index $(U)$ were calculated for each proportion of blood using Dose Estimate 5.1 software. The fractions of irradiated cells were also calculated for the estimated dose $(D)$ using several different $D_{0}$ value $(2.7 ; 3.8 ; 5.4)$ using
Chromosome Aberration Calculation Software (CABAS) version 2.0.

\section{RESULTS AND DISCUSSION}

The MN frequencies and distributions in all proportions of irradiated blood tested were presented at Table 2. It was clearly seen that in all proportion of irradiated bloods the $u$ values were significant overdispersion $(u>1.96)$. Value of $u$ varies from 7.93 to 26.2. In dicentric analysis it was well known that to determine the type of radiation exposure can be seen from $u$ value evaluation. In case of whole body exposure the $u$ value commonly follow Poisson distribution. A significant overdispersion is suggestive of partial irradiation for dicentric analysis and can be used to differentiate the homogeneously exposed samples from heterogeneously exposed samples [12]. In contrast for MNs assays the $u$ values commonly overdispere, as it can be seen in table 2 even at control group (100\%) the $u$ value still overdispere. The proportion of irradiated cells and estimated dose (D) with several different $D_{0}$ values $(2.7 ; 3.8 ; 5.4)$ using CABAS 2.0 were presented at Table 3. It can be seen that $\mathrm{D}_{0}$ value at 5.4 gave a results closest to the real proportion of irradiated bloods (Fig. 1).

Table 2. The MN frequencies and distributions in all proportions of irradiated blood.

\begin{tabular}{|c|c|c|c|c|c|c|c|c|c|c|c|c|}
\hline \multirow{2}{*}{$\begin{array}{c}\text { Donor } \\
\text { (Age, Sex) }\end{array}$} & \multirow{2}{*}{$\begin{array}{c}\% \\
\text { Irradiated } \\
\text { Bloods }\end{array}$} & \multirow{2}{*}{$\mathrm{BNC}$} & \multirow{2}{*}{$\mathrm{MN}$} & \multicolumn{6}{|c|}{ Distribution of $\mathrm{MN}$} & \multirow{2}{*}{$Y \pm \mathrm{SE}$} & \multirow{2}{*}{$\sigma^{2} / y \pm \mathrm{SE}$} & \multirow{2}{*}{$U$} \\
\hline & & & & 0 & 1 & 2 & 3 & 4 & 5 & & & \\
\hline \multirow{6}{*}{1 (30, Male) } & $5 \%$ & 2160 & 35 & 2135 & 18 & 5 & 1 & 1 & 0 & $0.016 \pm 0.005$ & $1.780 \pm 0.030$ & 26.200 \\
\hline & $10 \%$ & 2153 & 47 & 2114 & 33 & 4 & 2 & 0 & 0 & $0.022 \pm 0.004$ & $1.400 \pm 0.030$ & 13.400 \\
\hline & $15 \%$ & 2157 & 82 & 2089 & 55 & 12 & 1 & 0 & 0 & $0.038 \pm 0.005$ & $1.330 \pm 0.030$ & 10.900 \\
\hline & $20 \%$ & 2200 & 105 & 2118 & 64 & 14 & 3 & 1 & 0 & $0.048 \pm 0.008$ & $1.510 \pm 0.030$ & 16.800 \\
\hline & $30 \%$ & 2204 & 171 & 2080 & 88 & 27 & 7 & 2 & 0 & $0.078 \pm 0.010$ & $1.620 \pm 0.030$ & 20.800 \\
\hline & $100 \%$ & 2037 & 590 & 1599 & 313 & 102 & 19 & 4 & 0 & $0.290 \pm 0.016$ & $1.330 \pm 0.031$ & 10.600 \\
\hline \multirow{6}{*}{2 (43, Female) } & $5 \%$ & 2209 & 60 & 2161 & 39 & 7 & 1 & 1 & 0 & $0.027 \pm 0.006$ & $1.510 \pm 0.030$ & 17.000 \\
\hline & $10 \%$ & 2189 & 83 & 2122 & 56 & 8 & 1 & 2 & 0 & $0.038 \pm 0.006$ & $1.520 \pm 0.030$ & 17.200 \\
\hline & $15 \%$ & 2171 & 100 & 2088 & 69 & 11 & 3 & 0 & 0 & $0.046 \pm 0.007$ & $1.350 \pm 0.030$ & 11.700 \\
\hline & $20 \%$ & 2198 & 93 & 2123 & 61 & 11 & 2 & 1 & 0 & $0.042 \pm 0.006$ & $1.450 \pm 0.030$ & 15.100 \\
\hline & $30 \%$ & 2298 & 152 & 2175 & 98 & 21 & 4 & 0 & 0 & $0.066 \pm 0.007$ & $1.370 \pm 0.029$ & 12.500 \\
\hline & $100 \%$ & 2054 & 597 & 1612 & 317 & 101 & 19 & 4 & 1 & $0.291 \pm 0.016$ & $1.350 \pm 0.031$ & 11.300 \\
\hline \multirow{6}{*}{3 (52, Female) } & $5 \%$ & 2157 & 76 & 2097 & 47 & 10 & 3 & 0 & 0 & $0.035 \pm 0.006$ & $1.470 \pm 0.030$ & 15.400 \\
\hline & $10 \%$ & 2173 & 96 & 2099 & 58 & 11 & 4 & 1 & 0 & $0.044 \pm 0.008$ & $1.560 \pm 0.030$ & 18.600 \\
\hline & $15 \%$ & 2140 & 97 & 2065 & 58 & 13 & 3 & 1 & 0 & $0.045 \pm 0.008$ & $1.530 \pm 0.030$ & 17.500 \\
\hline & $20 \%$ & 2128 & 115 & 2029 & 84 & 14 & 1 & 0 & 0 & $0.054 \pm 0.006$ & $1.240 \pm 0.031$ & 7.930 \\
\hline & $30 \%$ & 2227 & 162 & 2100 & 98 & 24 & 4 & 1 & 0 & $0.073 \pm 0.009$ & $1.450 \pm 0.030$ & 14.900 \\
\hline & $100 \%$ & 2077 & 550 & 1664 & 304 & 86 & 18 & 5 & 0 & $0.265 \pm 0.015$ & $1.350 \pm 0.031$ & 11.400 \\
\hline
\end{tabular}


Table 3. Predicted fraction of irradiated cells and estimated dose $(D)$ with several different $D_{0}$ values $(2.7 ; 3.8 ; 5.4)$.

\begin{tabular}{|c|c|c|c|c|c|c|c|}
\hline \multirow{2}{*}{$\begin{array}{c}\text { Donor } \\
\text { (Age, Sex) }\end{array}$} & \multirow{2}{*}{$\begin{array}{c}\% \\
\text { Irradiated } \\
\text { Bloods }\end{array}$} & \multicolumn{2}{|c|}{$D_{0}=2.7$} & \multicolumn{2}{|c|}{$D_{0}=3.8$} & \multicolumn{2}{|c|}{$D_{0}=5.4$} \\
\hline & & $\begin{array}{l}\text { Estimated \% } \\
\text { Irradiated } \\
\end{array}$ & $\begin{array}{c}\text { Estimated Partial } \\
\text { Dose (Gy) }\end{array}$ & $\begin{array}{c}\text { Estimated \% } \\
\text { Irradiated }\end{array}$ & $\begin{array}{c}\text { Estimated Partial } \\
\text { Dose (Gy) }\end{array}$ & $\begin{array}{l}\text { Estimated \% } \\
\text { Irradiated } \\
\end{array}$ & $\begin{array}{l}\text { Estimated Partial } \\
\text { Dose (Gy) }\end{array}$ \\
\hline \multirow{5}{*}{$1(30$, Male $)$} & $5 \%$ & 10.16 & 4.3237 & 6.66 & 4.3237 & 4.86 & 4.3237 \\
\hline & $10 \%$ & 14.27 & 2.8037 & 10.99 & 2.8037 & 9.04 & 2.8037 \\
\hline & $15 \%$ & 23.27 & 2.8037 & 18.36 & 2.8037 & 15.32 & 2.8037 \\
\hline & $20 \%$ & 26.48 & 3.4517 & 19.96 & 3.4517 & 16.02 & 3.4517 \\
\hline & $30 \%$ & 37.33 & 4.1589 & 27.66 & 4.1589 & 21.69 & 4.1589 \\
\hline \multirow{5}{*}{$2(43$, Female $)$} & $5 \%$ & 16.74 & 3.1624 & 12.55 & 3.1624 & 10.10 & 3.1624 \\
\hline & $10 \%$ & 22.56 & 3.0624 & 17.36 & 3.0624 & 14.22 & 3.0624 \\
\hline & $15 \%$ & 27.52 & 2.7504 & 22.07 & 2.7504 & 18.62 & 2.7504 \\
\hline & $20 \%$ & 24.62 & 3.1127 & 18.98 & 3.1127 & 15.55 & 3.1127 \\
\hline & $30 \%$ & 35.34 & 3.0624 & 28.28 & 3.0624 & 23.72 & 3.0624 \\
\hline \multirow{5}{*}{3 (52, Female) } & $5 \%$ & 20.76 & 3.3090 & 15.55 & 3.3090 & 12.47 & 3.3090 \\
\hline & $10 \%$ & 24.68 & 3.5909 & 18.27 & 3.5909 & 14.47 & 3.5909 \\
\hline & $15 \%$ & 25.26 & 3.5449 & 18.81 & 3.5449 & 14.97 & 3.5449 \\
\hline & $20 \%$ & 33.48 & 2.3592 & 28.13 & 2.3592 & 24.58 & 2.3592 \\
\hline & $30 \%$ & 36.82 & 3.4045 & 28.85 & 3.4045 & 23.74 & 3.4045 \\
\hline
\end{tabular}

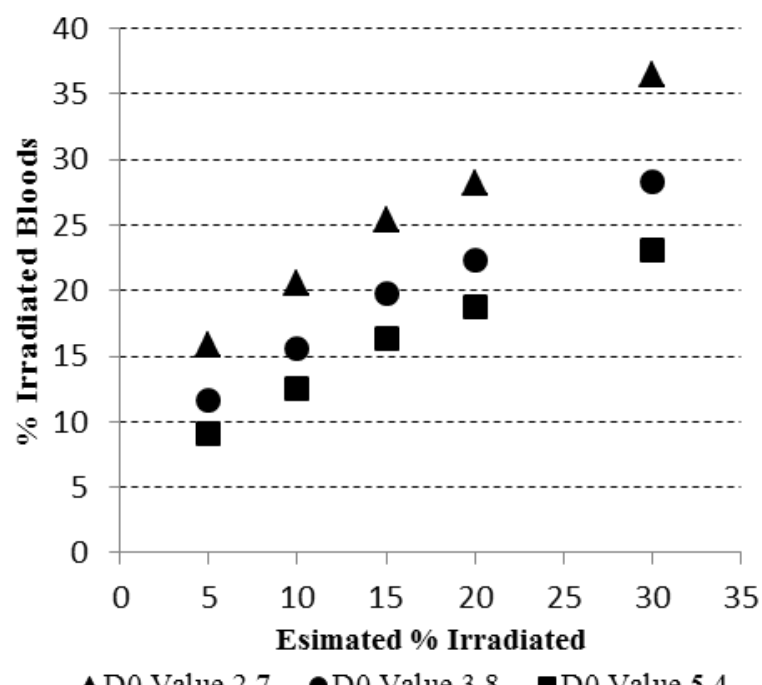

$\Delta$ D0 Value $2.7 \quad \bullet$ D0 Value $3.8 \quad$ DD 0 Value 5.4

Fig. 1. Estimate of percentage $(\%)$ irradiated compared to actual values irradiated using three different $D_{0}$ values, namely 2.7 (triangles), 3.8 (circles) and 5.4 (squares).

Even though the $D_{0}$ value of 5.4 gave a better results compared to others $D_{0}$ values, the predicted proportions of irradiated cells are still inaccurate. The factor that may have caused this phenomenon was the dose-response calibration curve used to predict the fraction of irradiated cells. In this study the dose-response calibration curve was from Pajic et al., [13]. Since the laboratory where this study took place did not have its own dose-response calibration curve for
MN, a calibration curve from another study is used here. Inaccuracy in fraction estimation was also reported using several $D_{0}$ value in the dicentric assay [14].

IAEA recommended that laboratories performing biological dose assessment using cytogenetic analysis should obtain their own dose-response calibration curve for different types and energies of radiation [5]. For that reason, and to obtain more accurate dose prediction (and prediction of proportion of irradiated cells in the case of partial body exposure) the laboratory used in this study now develops the dose-response calibration curve for micronuclei analysis. For dose estimation, the estimated doses value from all proportions in all donors was higher compared to the actual dose of 2 Gy (Fig. 2). A factor that may contribute to this result was the dose-response calibration curve used for dose estimation not being constructed in the laboratory. From the results of this study, it was clear that the radiation dose-response calibration curve for the MN analysis should be produced in the same laboratory. The laboratory previously successfully developed a dose-response calibration curve for dicentric analysis induced by gamma rays [15]. In order to establish a biodosimetry using MN analysis, the dose-response calibration curve for $\mathrm{MN}$ analysis must be constructed first. 


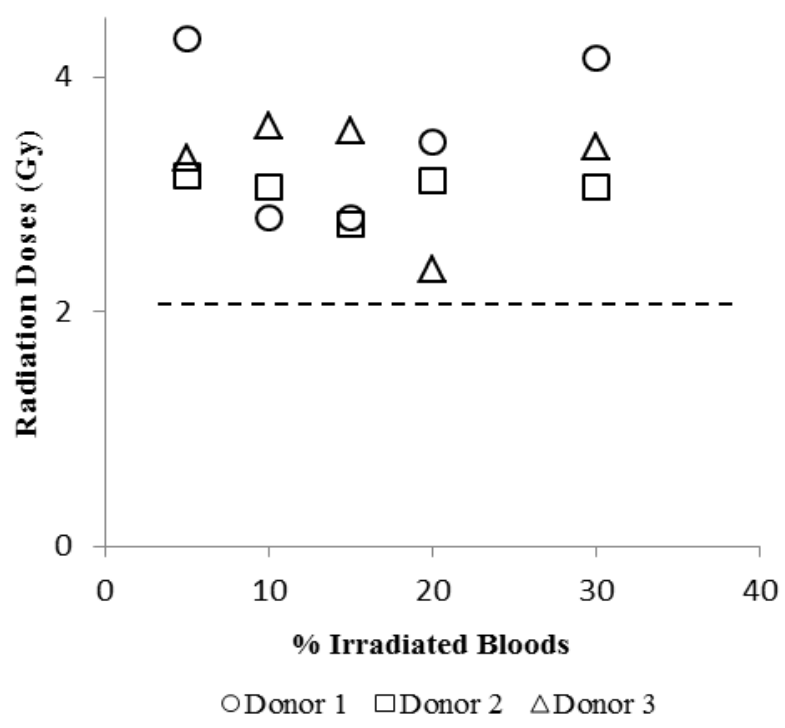

Fig. 2. Estimate of radiation dose values for all proportions of irradiated bloods from three different donors. The dashed line is the actual radiation dose of $2 \mathrm{~Gy}$.

The results show that the induced $\mathrm{MN}$ freuencies are proportional to the percentage of irradiated lymphocytes. For example, the total number of $\mathrm{MN}$ for $30 \%$ at donor 1 was 171 while for $100 \%$ was 590 . It can also be seen that most of binucleated cells contained a single MN. There are inter-individual differences among subjects that are influenced by different mutagen sensitivity and DNA repair capacity. It was known that $\mathrm{MN}$ frequency in females tends to be higher relative to males by a factor approximately 1.4. Researchers suspect that the higher MN frequency in females correlated with greater tendency of the inactive $\mathrm{X}$-chromosome to be lost as an $\mathrm{MN}$ relative to other chromosomes, and to the fact that females have two copies of the chromosome compared to only one in males $[16,17]$.

A study conducted by Jones et al. [18] showed that in $19.9 \%$ of the cells scored at least one sex chromatin-positive MN was present. Another study by Hando et al. [19] found that X-chromosomes present in $72.2 \%$ of the $\mathrm{MN}$ scored and that a significant increase occurred with age in the number of MNs containing an $\mathrm{X}$-chromosome. The increase of $\mathrm{MN}$ with age is due to a combination of several factors, namely: (i) the cumulative effect of acquired mutations in genes involved in DNA repair, and: (ii) numerical and structural aberrations in chromosomes caused by exposure to endogenous genotoxins, inadequate nutrition, exposure to environmental or occupational genotoxins, and a wide range of unhealthy lifestyle factors [16].
Interestingly, from our results the total $\mathrm{MN}$ in the male was higher compared to average of total MN from the two females. Age also did not exhibit influence in our study as can be seen that the total $\mathrm{MN}$ in donor 3 was lower compared to other donors. Since in this study the number of sample donors only consisted of three people, it is possible that influence of sex and age to total MN cannot be seen from this study. Further studies should be conducted to verify the effect of sex and age factors to number of $\mathrm{MN}$ in human peripheral lymphocytes. Here an evaluation of micronuclei for estimating the dose of radiation to lymphocytes is described. Micronuclei are only expressed in cells that proceed to complete nuclear division. This assay has emerged as one of the preferred methods for assessing chromosomal damage because they enable both chromosome loss and chromosome breakage to be measured reliably.

Moreover, this technique is useful for determining irradiation dosage by examining a large number of binucleated cells faster and using simpler techniques than chromosome aberrations. The technique is very easy to use when a large number of cells must be examined for routine monitoring of workers exposed to radiation [20,21] as $\mathrm{MN}$ is a good tool for cancer risk prediction as well as for studying genotoxicity and cytotoxicity as well as studies on genomic damage by chemicals in general [22].

\section{CONCLUSION}

Overall, it can be concluded from this study that biodosimetry using MN assay can be used to estimate the radiation dose in partial body exposure. However, it was not possible to distinguish between partial or total body exposures using Poisson or overdispersion distribution as the basis when conducting biodosimetry using $\mathrm{MN}$ assay. An optimal $D_{0}$ value was also calculated in this study and it can be seen that from this study that a $D_{0}$ value of 5.4 gave more accurate results compared with 2.7 and 3.8. To obtain more accurate results the laboratory used should construct the dose-response calibration curve for $\mathrm{MN}$ analysis in further studies.

\section{ACKNOWLEDGMENT}

The authors would like to thank Mrs. Yanti Lusiyanti, Center for Radiation Safety Technology and Metrology, National Nuclear Energy Agency of Indonesia for technical assistance. 


\section{REFERENCES}

1. Romero, O. Garcia, A. Lamadrid et al., J. Radiat. Res. 54 (2013) 863. DOI: 10.1093/ jrr/rrt032.

2. T. Fernandes, D. Loyd and A. Amaral, Brazilian Arch. Biol. Technol. 51 (2008) 97. DOI: http://dx.doi.org/10.1590/S1516-8913200 8000700016.

3. S. Roch-Lefèvre, F. Pouzoulet, A. Giraudet et al., Br. J. Radiol. 83 (993) (2010) 759. DOI:http://dx.doi.org/10.1259/bjr/210225597.

4. M. Valente, J. Denis, N. Grenier et al., PLoS One 10 (2015) 1. DOI: 10.1371/journal. pone.0132194.

5. Anonymous, Cytogenetic Dosimetry: Applications In Preparedness For And Response To Radiation Emergencies, IAEA, 2011.

6. I. Silva-Barbosa, S. Pereira-Magnata, A. Amaral et al., Genet. Mol. Biol. 28 (2005) 452. DOI: http://dx.doi.org/10.1590/S141547572005000300021.

7. S. Senthamizhchelvan, G. Pant, G. Rath et al., Phys. Medica 25 (2009) 82. DOI: http://dx.doi.org/10.1016/j.ejmp.2008.05.004.

8. J.M. Sullivan, P.G.S. Prasanna, M.B. Grace et al., Health Phys. 105 (2013) 1. DOI: 10.1097/HP.0b013e31829cf221.

9. K. Rothkamm, C. Beinke, H. Romm et al., Radiat. Res. 180 (2013) 111. DOI: 10.1667/ RR3231.1.

10. G.T. Selvan, M. Bhavani, J. Vijayalakshmi et al., Dose-Response 12 (2014) 498. DOI: $10.2203 /$ dose-response.13-060.Selvan.
11. S.W. Lue, M. Repin, D.J. Brenner et al., Radiat. Res. 184 (2015) 134.

12. A. Vaurijoux, E. Gregoire, S. Roch-Lefevre et al., Radiat. Res. 178 (2011) 357. DOI: 10.1667/RR2728.1.

13. J. Pajic, B. Rakic, D. Jovicic et al., Mutat. Res. Genet. Toxicol. Environ. Mutagen. 773 (2014) 23. DOI: 10.1016/j.mrgentox. 2014.07.009.

14. J. Barquinero, L. Barrios, M. Caballin et al., Int. J. Radiat. Biol. 71 (1997) 435.

15. Y. Lusiyanti, Z. Alatas, M. Lubis et al., Atom Indonesia 39 (2013) 124. DOI: http://dx.doi.org/10.17146/aij.2013. 254.

16. M. Fenech and S. Bonassi, Mutagenesis 26 (2011) 43. DOI: 10.1093/mutage/geq050.

17 H. Nefic and I. Handzic, Mutat. Res. 753 (2013) 1. DOI: 10.1016/j.mrgentox.2013. 03.001 .

18. K. Jones, T. York and C. Jackson-Cook, Mutat. Res. 747 (2012) 207. DOI: 10.1016/ j.mrgentox.2012.05.004.

19. J. Hando, J. Nath and J. Tucker, Chromosoma 103 (1994) 186.

20. A. Vral, M. Fenech, H. Thierens et al., Mutagenesis 26 (2011) 11. DOI: 10.1093/ mutage/geq078.

21. K. Rawojc, D.M. Tarnawska, J.U. Miszczyk et al., Nukleonika 60 (2015) 643. DOI: 10.1515/nuka-2015-0105.

22. S. Bonassi, R. El-zein, C. Bolognesi et al., Mutagenesis 26 (2011) 93. DOI: 10.1093/ mutage/geq075. 